\title{
Organizations and Care
}

\section{Does the Impact of Managed Care on Substance Abuse Treatment Services Vary by Provider Profit Status?}

\author{
Todd A. Olmstead and Jody L. Sindelar
}

Objective. To extend our previous research by determining whether, and how, the impact of managed care (MC) on substance abuse treatment (SAT) services differs by facility ownership.

Data Sources. The 2000 National Survey of Substance Abuse Treatment Services, which is designed to collect data on service offerings and other characteristics of SAT facilities in the U.S. These data are merged with data from the 2002 Area Resource File, a county-specific database containing information on population and $\mathrm{MC}$ activity. We use data on 10,513 facilities, virtually a census of all SAT facilities.

Study Design. For each facility ownership type (for-profit [FP], not-for-profit [NFP], public), we estimate the impact of MC on the number and types of SAT services offered. We use instrumental variables techniques that account for possible endogeneity between facilities' involvement in $\mathrm{MC}$ and service offerings.

Principal Findings. We find that the impact of MC on SAT service offerings differs in magnitude and direction by facility ownership. On average, MC causes FPs to offer approximately four additional services, causes publics to offer approximately four fewer services, and has no impact on the number of services offered by NFPs. The differential impact of MC on FPs and publics appears to be concentrated in therapy/counseling, medical testing, and transitional services.

Conclusion. Our findings raise policy concerns that MC may reduce the quality of care provided by public SAT facilities by limiting the range of services offered. On the other hand, we find that FP clinics increase their range of services. One explanation is that $\mathrm{MC}$ results in standardization of service offerings across facilities of different ownership type. Further research is needed to better understand both the specific mechanisms of MC on SAT and the net impact on society.

Key Words. Substance abuse treatment, wraparound services, managed care, profit status

This paper extends our previous research by determining whether, and how, the impact of managed care (MC) on service offerings varies by the profit status of the substance abuse treatment (SAT) facility (Olmstead, White, and 
Sindelar 2004). It adds to the literature on the impact of profit status on the provision of health care and extends this literature to the relatively less studied area of SAT. This topic is important for several reasons. Substance abuse is an important and costly problem, harming abusers as well as their families, friends, and society (Harwood, Fountain, and Livermore 1998; ONDCP 2001). Effective treatment can reduce many of these costs (IOM 1990; ONDCP 1996; National Consensus Development Panel on Effective Medical Treatment of Opiate Addition 1998; NIDA 1999; French et al. 2000; JofreBonet and Sindelar 2001). In addition, MC has been growing rapidly in the SAT field, and there is some concern that MC's emphasis on cost-containment may result in fewer services offered, thus reducing treatment effectiveness (Alexander, Lemak, and Campbell 2003; Olmstead, White, and Sindelar 2004). Reduced effectiveness, in turn, could have a negative impact on society through increases in crime, welfare dependency, and spread of infectious diseases. Importantly, the impact of MC on SAT service offerings may differ systematically by provider profit status.

SAT is provided by a mix of for-profit (FP), not-for-profit (NFP), and public providers. The majority of the providers in the SAT market are NFPs and the fewest number are publics. However, publics tend to be larger in terms of people treated per clinic. Characteristics of SAT facilities vary systematically by ownership type. This may occur for several reasons, including differences in mission, client mix, and opportunities and constraints imposed by their profit status. FPs, for example, tend to serve clients who have relatively fewer comorbidities and are privately insured or able to pay for care out-ofpocket, while publics tend to treat clients who have relatively more comorbidities and whose care is supported by government financing (Rodgers and Barnett 2000; Wheeler and Nahra 2000; Ettner et al. 2003). These differences suggest that the impact of MC may vary by profit status.

This paper focuses on how MC differentially affects the range of services offered by providers with different ownership types. Range of services is a key measure of treatment effectiveness (Olmstead, White, and Sindelar 2004). Treatment effectiveness is improved by the availability of a range of services, including social and medical services, necessary to meet the wide spectrum of needs faced by drug-dependent individuals (McLellan et al. 1993, 1998, 1999; Milby et al. 1996; Gould, Levine, and McLellan 2000; Marsh, D'Aunno, and

Address correspondence to Todd A. Olmstead, Ph.D., Associate Research Scientist, Yale School of Public Health, 60 College Street, PO Box 208034, New Haven, CT 06520-8034. Jody L. Sindelar, Ph.D., Professor, is with the Yale School of Public Health, New Haven, CT. 
Smith 2000; Smith and Marsh 2002). While there is a growing interest in the effects of MC on SAT generally, relatively few studies have focused on the effects of MC on the number and type of SAT services offered, and none of these examine whether and by how much the effect varies by the ownership type of the provider.

This study presents empirical evidence on these issues. Data from more than 10,000 SAT facilities in the U.S. are used in these analyses. We use the instrumental variables (IV) approach to identify the effects of MC on SAT service offerings. We examine the offerings of 26 different services grouped into five categories: assessment, therapy/counseling, medical testing, transitional, and other ancillary services. Because our dataset is large and covers most SAT facilities in the U.S., our statistical power is high and our results are likely to be widely generalizable. Our findings should be of interest to policy makers, researchers, patients, public and private payers, clinics and clinicians.

\section{BACKGROUND}

Research shows that the profit status of SAT facilities is associated with differences in clientele, access to care, and service offerings. For example, FPs cater to and serve clients that are typically privately insured (or able to pay for care out-of-pocket) and have relatively fewer comorbidities, while publics tend to treat clients whose care is supported by government financing and who have relatively more comorbidities (Rodgers and Barnett 2000; Wheeler and Nahra 2000; Ettner et al. 2003). FPs are more likely than publics both to provide "treatment on demand" (wait time of 48 hours or less for treatment entry) and to turn patients away because of inability to pay (Friedmann et al. 2003). And FPs are significantly less likely than publics to offer comprehensive services, possibly because FP clientele have less need for these services (Friedmann, Alexander, and D'Aunno 1999; Friedmann et al. 2003; Olmstead and Sindelar 2004).

Several studies focus on the relationship between $\mathrm{MC}$ and the number or type of services offered at SAT facilities. Friedmann et al. (2003) find that MC is associated with greater availability of mental health services and routine medical care but not financial counseling, employment counseling, or physical exams. Durkin (2002) finds that MC is associated with a reduction in the likelihood of providing employment counseling and financial counseling, and an increase in the likelihood of providing routine medical care and physical 
exams. Olmstead, White, and Sindelar (2004) examine a broad array of 26 SAT services and find that: (1) MC causes SAT facilities to offer, on average, approximately two fewer services overall, and (2) this effect is concentrated primarily in tests for infectious diseases (i.e., TB, HIV/AIDs, and STDs).

Providers of different ownership types have systematically varying goals, opportunities, and constraints based on their profit status. As noted above, research shows that these organizational differences, in turn, can produce differences in client mix, pricing, funding, access to care, and range of service offerings. Importantly, these organizational differences may also produce systematically different organizational responses to $\mathrm{MC}$, suggesting that facilities should be analyzed allowing for a differential response by ownership type.

\section{METHODS}

\section{Data}

Data on SAT facilities were obtained from the 2000 National Survey of Substance Abuse Treatment Services (NSSATS), a national survey administered by the Substance Abuse and Mental Health Services Administration (SAMHSA) that collects information on the location, characteristics, and use of SAT facilities and services in the U.S. (USDHHS 2002b). The list frame for the 2000 NSSATS is the Inventory of Substance Abuse Treatment Services, a continuously updated census of all known SAT facilities, both public and private, throughout the U.S. and its territories. Analyses were performed separately for facilities with public ownership, private FP ownership, and private NFP ownership.

Of the original census of 14,622 SAT facilities deemed eligible for the survey, 13,428 (92 percent) completed the survey. ${ }^{1}$ Of these, we exclude facilities located in other U.S. jurisdictions $(n=120),{ }^{2}$ owned by federal or tribal governments $(n=481)$, or offering detoxification services only $(n=41)$. An additional 2,273 facilities are excluded because of missing data, resulting in a final study sample comprising 10,513 SAT facilities.

We supplement the 2000 NSSATS data on facility characteristics with county-specific data from the 2002 Area Resource File (USDHHS 2002a), a database containing information on population and $\mathrm{MC}$ activity in the U.S.

\section{Outcomes}

The 2000 NSSATS records whether a facility offers each of 26 different SAT services and groups these individual services into five categories: assessment, 
therapy/counseling, medical testing, transitional, and other ancillary. Accordingly, we use six outcome variables to measure service offerings at a facility. The first outcome variable is the total number of services offered at the facility (ranging from 1 to 26), while the remaining five outcome variables represent the number of services offered within each of the five service categories. Table 1 lists each of the outcome variables used in this study along with the specific services belonging to each category.

\section{Regressors}

We control for a wide variety of important facility and county-specific characteristics. Facility characteristics include the presence of managed care, focus, setting, modality, accreditation, licensure, size, types of payment accepted, and willingness to offer payment assistance. Our measure of managed care is whether or not the facility has a relationship with an managed care organization, $M C$, set to 1 if a facility has at least one agreement or contract with a managed care organization to provide SAT services, and 0 otherwise. Facility foci include substance abuse, mental health, general health, mixed mental health and substance abuse, and other. Settings include hospital, solo practice, and halfway house. Modalities include hospital inpatient, nonhospital residential, outpatient, and methadone/LAAM. Finally, types of payment accepted include cash, private health insurance, Medicaid, Medicare, statefinanced health insurance, and public funds (not including Medicaid and Medicare).

County-specific characteristics include population size, population density (people per square mile), metropolitan area, competition among facilities (measured using Herfindahl indices), and MC activity (measured using the number of Medicare MC and HMO enrollees in the county). ${ }^{3}$ Table 1 lists each of the regressors used in this study. We control for these variables based on earlier studies (see Olmstead, White, and Sindelar 2004 for a conceptual framework).

\section{Estimation}

We first present descriptive data by facility ownership type (i.e., publics, FPs, and NFPs). Facilities are further subdivided by the presence of MC. Proportions are given for categorical variables and means for continuous variables. By comparing the characteristics of facilities with and without MC, we can get a sense of whether differential selection of facilities into relationships with MC is likely to confound the relationship between MC and service offerings. 


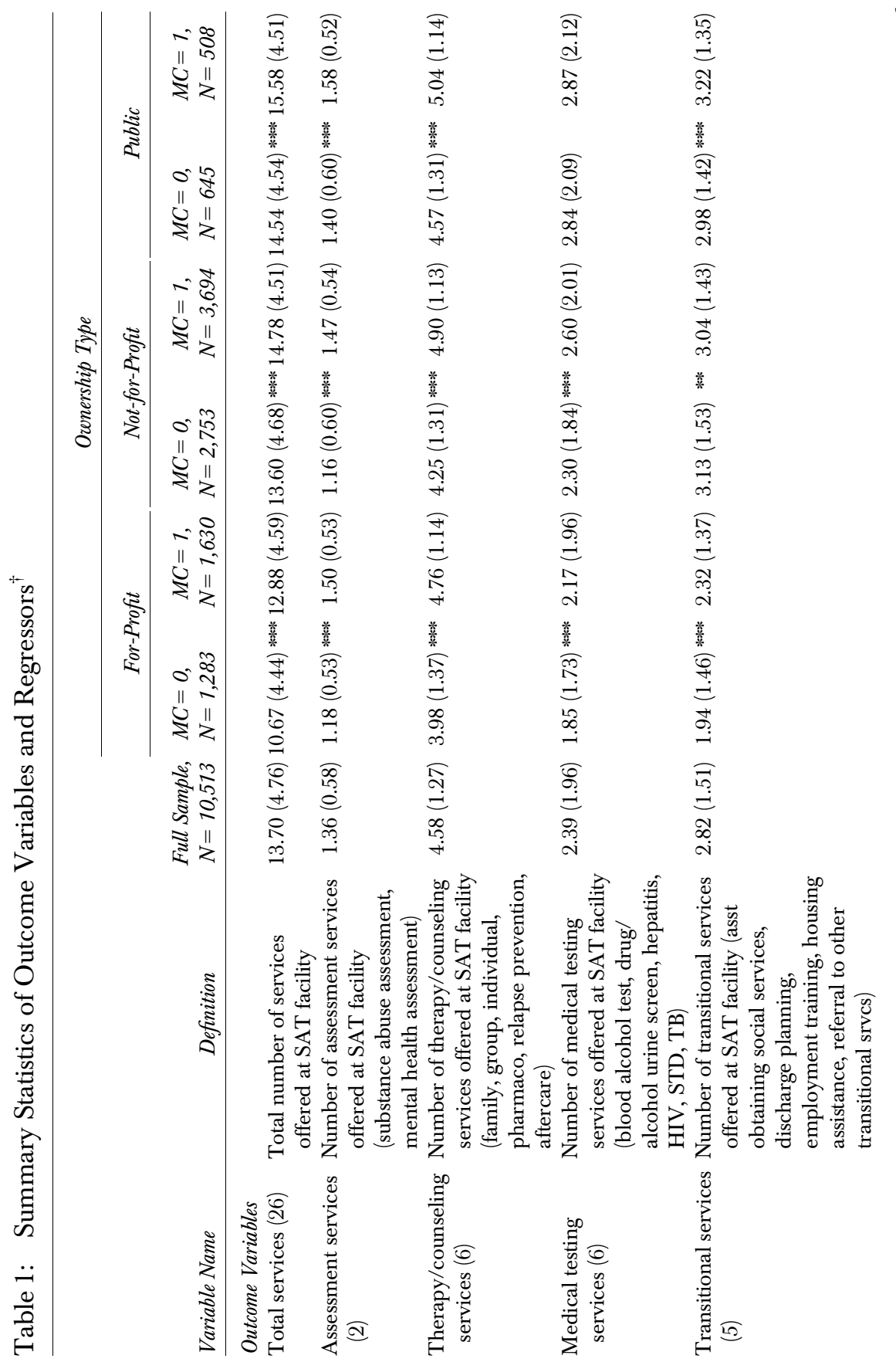




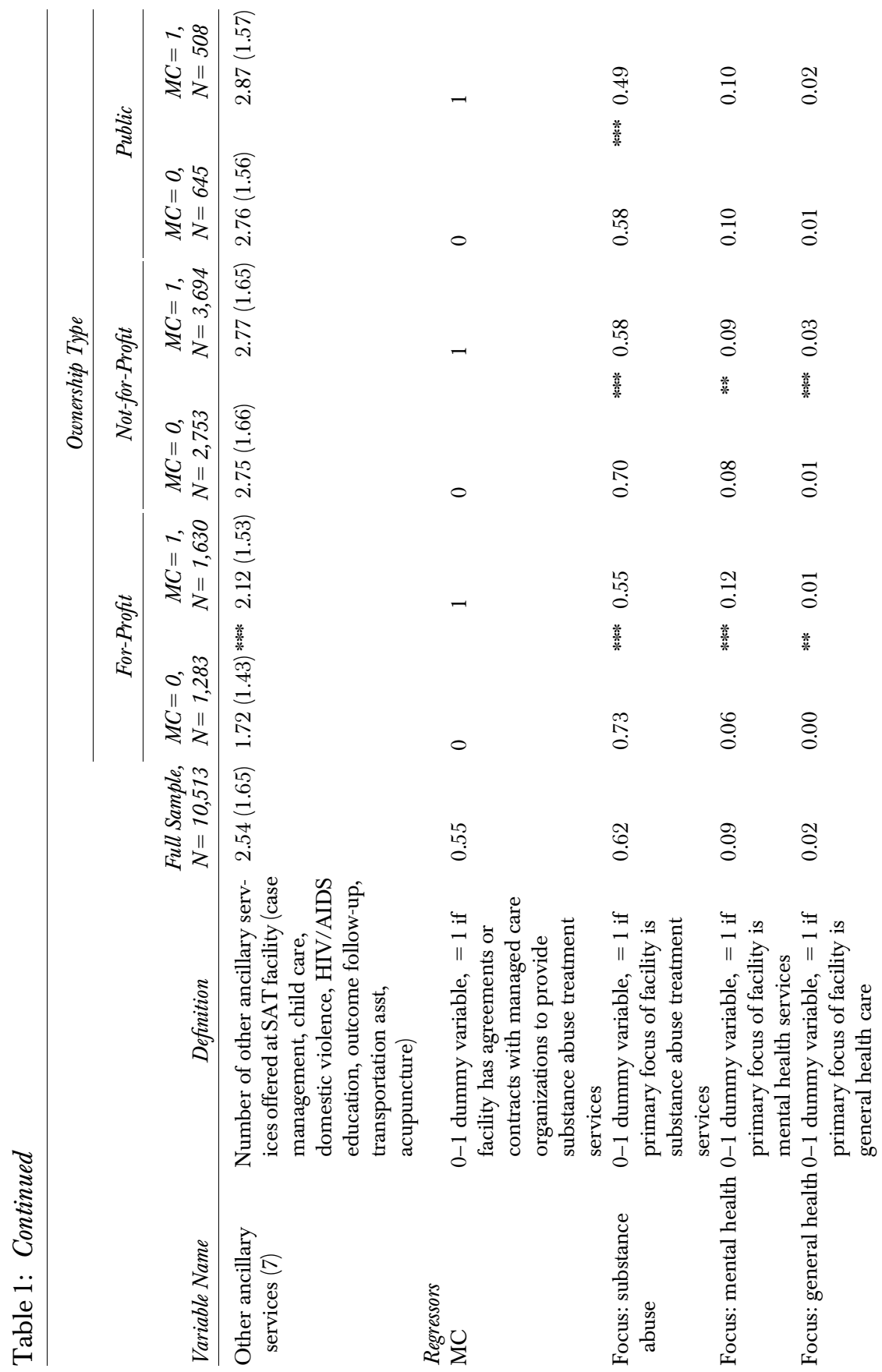




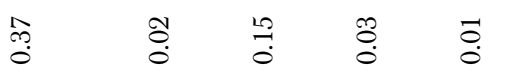

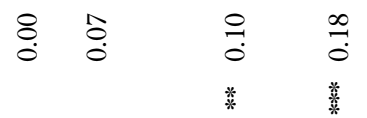

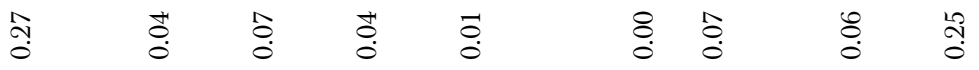

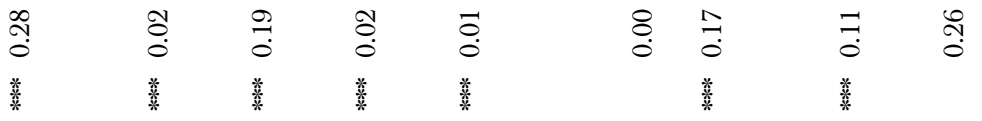

낭 菅

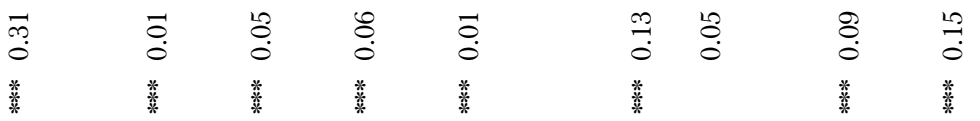

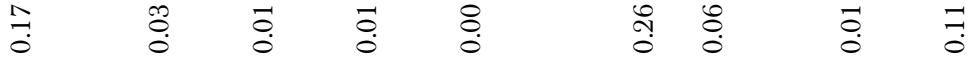

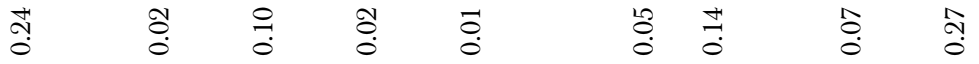

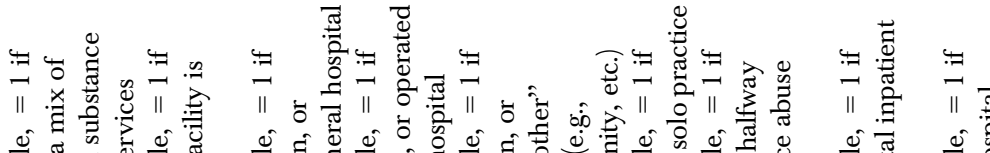

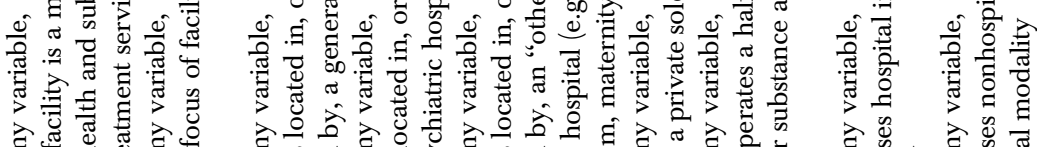

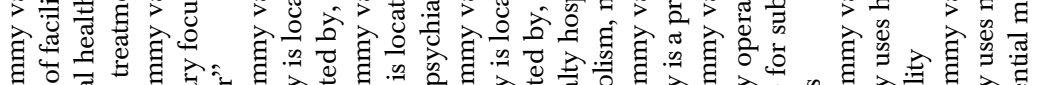

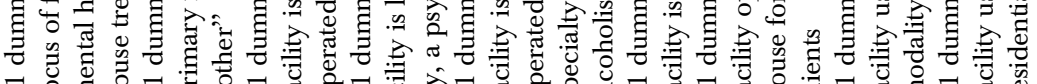

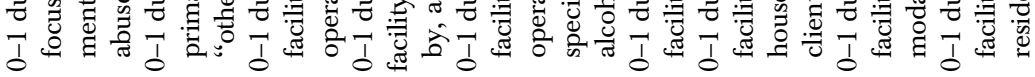

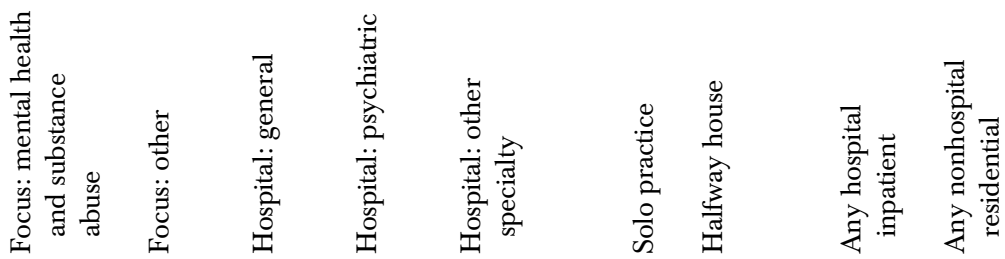




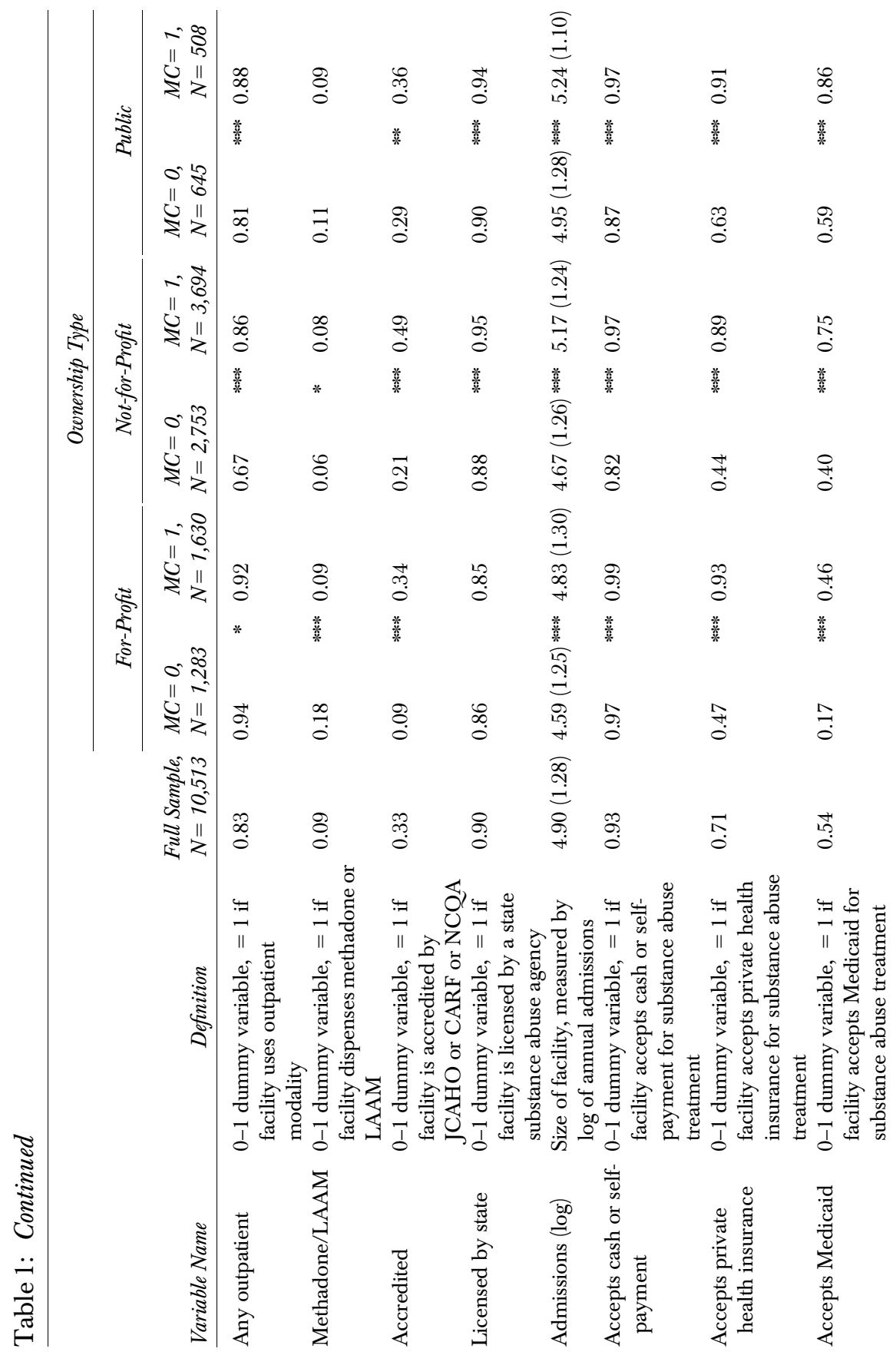




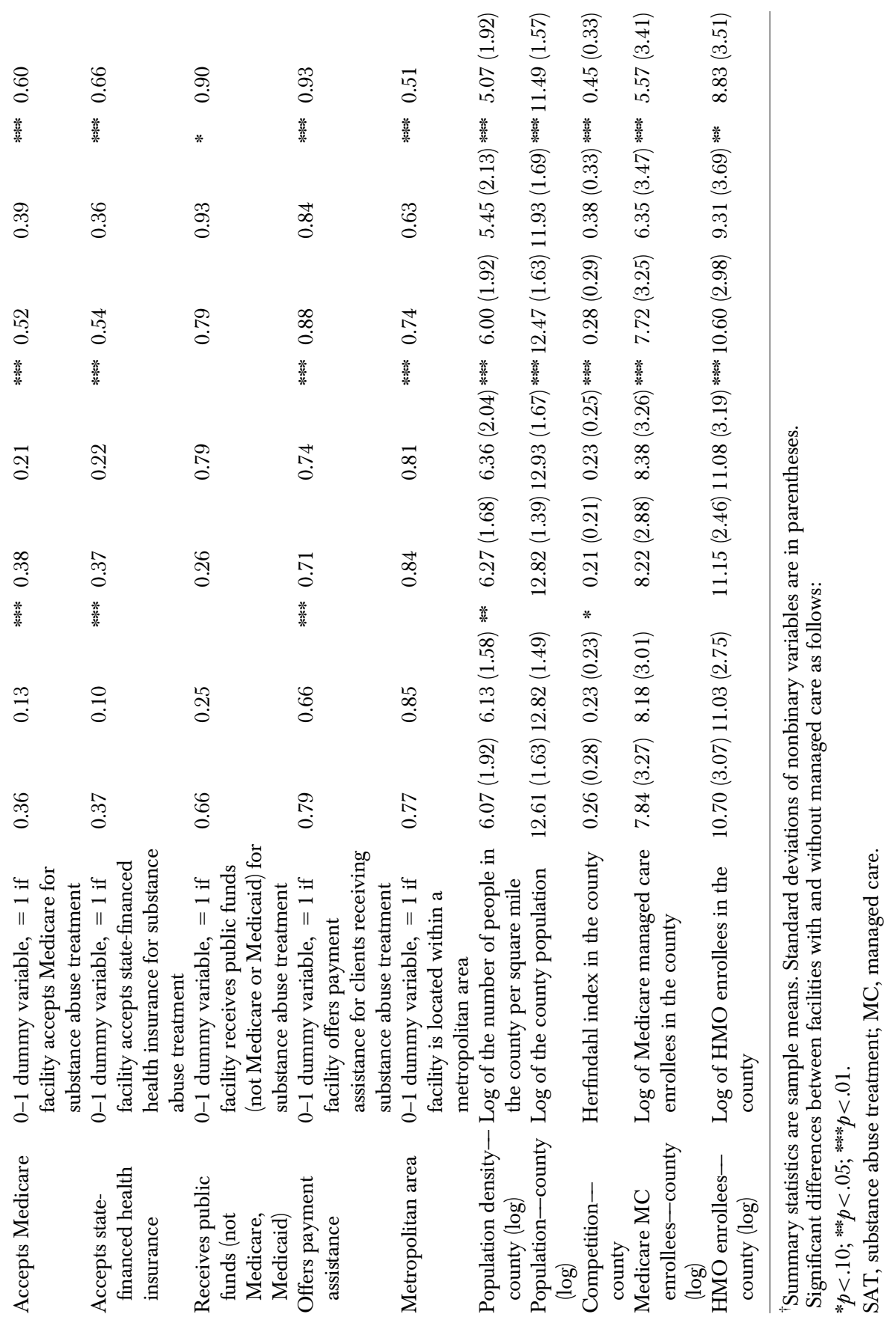


We then use a two-equation IV approach to estimate the effect of $\mathrm{MC}$ on the outcome variables. This approach allows us to account for possible endogeneity between a facility's involvement in MC and service offerings. Endogeneity would be present, for example, if $\mathrm{MC}$ is attracted to facilities with an unobserved (to the analyst) propensity to offer more (or fewer) services. For example, MC may be attracted to facilities with administrative sophistication, a trait which is unobserved to the researcher but correlated with both service offerings and MC. With valid instruments, the IV approach accounts for endogeneity and produces consistent estimates of the causal effect of MC on service offerings (Davidson and MacKinnon 1993, p. 218; Greene 2003, p. 86). The IV approach is used frequently in economic applications and is becoming increasingly common in health care evaluations (McClellan and Newhouse 2000).

We use the following two-equation model:

$$
\begin{aligned}
& Y=\beta X+\gamma M C+\varepsilon \\
& M C=\alpha X+\kappa Z+\mu
\end{aligned}
$$

where $Y$ is the outcome variable under study, $M C$ is a dummy variable indicating the presence of managed care at the facility, $X$ is a vector of facility and environmental characteristics, $\varepsilon$ is the error term for equation (1) that captures unobserved determinants of $Y, Z$ is a vector of instruments that influences the presence of managed care but is uncorrelated with $\varepsilon$, and $\mu$ is the error term for equation (2).

The two-equation system is estimated using a full-maximum-likelihood "treatment effects" model (Maddala 1983) that considers the effect of an endogenously chosen binary treatment $(M C)$ on another endogenous, fully observed, continuous variable (number of offered services). Facilities are clustered by county to account for possible spatial correlation among facilities operating in the same geographic area.

We estimate separate models for each group of facilities (publics, FPs, and NFPs). The same explanatory variables are used across the different ownership types. By estimating separate regressions for each profit status, we allow the coefficients on all the independent variables to differ by ownership type.

The IV approach requires finding one or more variables to be used as instruments, $Z$, which substantially affect $M C$ but have no direct impact on $Y$. We use two different county-specific instruments in our model: number of Medicare MC enrollees and number of HMO enrollees. Given that we control for county population and density, the number of Medicare MC (or HMO) enrollees is, in essence, a percentage. 
Both instruments plausibly satisfy the first correlation condition inasmuch as SAT facilities in counties with a large number ("percentage") of Medicare MC or HMO enrollees are more likely to have agreements or contracts with managed care than their counterparts in counties with relatively few Medicare MC or HMO enrollees. Similar county-specific environmental factors (e.g., local tastes, state/local laws, demographics) could cause this correlation. Spillover effects of many kinds could increase the favorable climate for managed care in SAT. As for the second condition, it seems plausible that the number of Medicare MC enrollees in a given county is unlikely to directly influence the service-offering decisions at SAT facilities in that county. Medicare covers primarily those 65 or older and SAT facilities treat very few elderly (approximately 1.5 percent of SAT clients are 65 or older). Similarly, there is likely to be relatively little overlap between HMO enrollees and SAT clients (e.g., 11 percent of the total population in the U.S. is drug dependent and only a fraction of them seek SAT).

We assess formally the validity of our instruments by testing for the presence of bias due to weak instruments. ${ }^{4} \mathrm{We}$ also conduct a standard overidentification test of the joint null hypothesis that equation (1) is specified correctly and that both instruments are valid. In general, overidentification tests implicitly compare estimates obtained using all instruments to estimates obtained using a subset of instruments that just identifies the model (i.e., one instrument for each endogenous variable). If all instruments are valid, then the two sets of estimates should differ by sampling error only (Wooldridge 2002, p. 123). Rejecting the null hypothesis that the two sets of estimates are the same raises serious concerns about the validity of at least one of the instruments in the overall set. On the other hand, failing to reject the null gives us some confidence in the validity of the overall set of instruments inasmuch as they all "tell the same story." As it is possible for the instruments to converge to similar incorrect estimates (i.e., they all tell the same story, but that story is incorrect), failing to reject the null does not by itself validate the instruments. However, if we have reason to believe, based on theoretical considerations, that one of the instruments yields correct estimates (i.e., the instrument is valid), then by extension, the other instruments must also be valid. ${ }^{5}$

\section{RESULTS}

\section{Descriptive Data by Facility Ownership}

Table 1 shows that, for each ownership type, $\mathrm{MC}$ is associated with more total services and, in most cases, more services within each specific category. For 
example, $\mathrm{MC}$ is associated with 2.2 more total services in FPs, 1.2 more total services in NFPs, and 1.0 more total services in publics. However, as shown in Table 1, facilities with and without MC differ systematically in other important ways as well. For each ownership type, for example, facilities with MC contracts are more likely to be larger, affiliated with a hospital, accredited, and to focus on both substance abuse and mental health. These factors could be associated with the availability of more services, thereby explaining the positive association between MC and services. Thus, we need to control for relevant covariates when estimating the impact of $\mathrm{MC}$ on service offerings. Moreover, $\mathrm{MC}$ is likely to be endogenously determined. That is, there may be unobserved factors that affect both the availability of services and the presence of MC. We now turn to the IV models.

\section{Specifications Controlling for Facility Characteristics}

Total Services. When we control for observed covariates and use IV to account for possible endogeneity, the impact of $\mathrm{MC}$ on total services varies in magnitude and direction by facility ownership. Table 2 shows that, on average, MC significantly increases the range of services offered at FPs by 3.8 services, has no significant impact on the total number of services offered at NFPs, and significantly reduces the range of services offered at publics by 3.7 services. These findings are quite different from the associations portrayed in the raw data in Table 1.

$F$-statistics for both the FP and NFP specifications are above 10.0, indicating that there is unlikely to be any bias due to weak instruments in these models (Staiger and Stock 1997). Although there may be some bias due to weak instruments in the model for publics, this bias is probably small inasmuch as the corresponding $F$-statistic is statistically significant and much larger than 1.0 (Bound, Jaeger, and Baker 1995). Importantly, all three models pass the overidentification test (Davidson and MacKinnon 1993; 2004), adding reassurance (but not proof) that equation (1) is specified correctly and that both instruments are valid.

Service Categories. Table 3 displays the results, for each ownership type, of the IV models corresponding to the specific service categories. We report only the coefficients of $\mathrm{MC}$ and suppress the coefficients on the control variables to focus on the key results.

It appears that the differential impact of $\mathrm{MC}$ on the total number of services offered by FPs and publics is concentrated primarily in the therapy/ counseling, medical testing, and transitional service categories. That is, within 
Table 2: Effects of Managed Care on Total Services-By Ownership

\begin{tabular}{|c|c|c|c|c|c|c|}
\hline \multirow[b]{3}{*}{ Variable Name } & \multicolumn{2}{|c|}{$\begin{array}{l}\text { For-Profit, } \\
N=2,913\end{array}$} & \multicolumn{2}{|c|}{$\begin{array}{l}\text { Not-for-Profit, } \\
N=6,447\end{array}$} & \multicolumn{2}{|c|}{$\begin{array}{c}\text { Public, } \\
N=1,153\end{array}$} \\
\hline & & $P-$ & & $P-$ & & $P-$ \\
\hline & Coefficient & Value & Coefficient & Value & Coefficient & Value \\
\hline Managed care & 3.818 & .000 & -0.889 & .348 & -3.725 & .001 \\
\hline Focus: substance abuse $^{\dagger}$ & -0.351 & .666 & 0.587 & .087 & -0.023 & .976 \\
\hline Focus: mental health ${ }^{\dagger}$ & -0.976 & .280 & 0.328 & .391 & -0.495 & .577 \\
\hline Focus: general health ${ }^{\dagger}$ & 0.246 & .830 & 2.436 & .000 & 2.801 & .011 \\
\hline Focus: mental and substance ${ }^{\dagger}$ & 0.173 & .835 & 1.394 & .000 & 0.969 & .241 \\
\hline Hospital: general $^{\ddagger}$ & 1.271 & .019 & -0.020 & .946 & 1.074 & .059 \\
\hline Hospital: psychiatric ${ }^{\ddagger}$ & 1.729 & .009 & 0.941 & .022 & 2.317 & .007 \\
\hline Hospital: other specialty ${ }^{\ddagger}$ & -1.535 & .036 & 1.121 & .044 & 2.315 & .053 \\
\hline Solo practice & -0.526 & .013 & N/A & & N/A & \\
\hline Halfway house & 1.074 & .017 & 0.063 & .758 & 0.357 & .511 \\
\hline Any hospital inpatient & 2.450 & .000 & 2.622 & .000 & 0.833 & .229 \\
\hline Any nonhospital residential & 3.361 & .000 & 2.960 & .000 & 2.240 & .000 \\
\hline Any outpatient & 0.610 & .161 & 1.034 & .000 & 0.060 & .911 \\
\hline Methadone/LAAM dispensed & 3.542 & .000 & 2.277 & .000 & 1.997 & .000 \\
\hline Accredited & 0.613 & .007 & 0.705 & .000 & 0.900 & .014 \\
\hline Licensed by state & 1.123 & .000 & 0.716 & .002 & 1.070 & .050 \\
\hline Admissions (log) & 0.346 & .000 & 0.326 & .000 & 0.525 & .000 \\
\hline Accepts cash or self-payment & -0.742 & .296 & -0.904 & .000 & 0.599 & .388 \\
\hline Accepts private health insurance & -0.525 & .133 & 0.642 & .099 & 2.047 & .000 \\
\hline Accepts Medicaid & 0.281 & .239 & 0.920 & .000 & 0.600 & .213 \\
\hline Accepts Medicare & 0.251 & .282 & 0.545 & .002 & 0.262 & .503 \\
\hline Accepts state-financed health insurance & 0.529 & .011 & 0.721 & .000 & 0.784 & .025 \\
\hline $\begin{array}{l}\text { Receives public funds (not Medicare, } \\
\text { Medicaid) }\end{array}$ & 0.545 & .013 & 1.235 & .000 & 0.971 & .113 \\
\hline Offers payment assistance & 1.108 & .000 & 0.936 & .000 & 1.286 & .017 \\
\hline Metropolitan area & -0.133 & .663 & -0.472 & .037 & -0.453 & .347 \\
\hline Population density - county (log) & 0.052 & .498 & 0.239 & .006 & 0.249 & .119 \\
\hline Population-county (log) & 0.080 & .538 & 0.149 & .168 & 0.434 & .112 \\
\hline Competition-county & 0.722 & .199 & -0.805 & .033 & 0.970 & .226 \\
\hline Constant & 4.129 & .030 & 4.066 & .001 & -0.209 & .945 \\
\hline$F$-statistic for instruments (statistic, $p$-value) & 10.88 & .004 & 49.49 & .000 & 5.35 & .069 \\
\hline Test of overidentification (statistic, $p$-value) & 1.12 & .289 & 2.57 & .109 & 0.23 & .633 \\
\hline
\end{tabular}

"Excluded category is "other."

"Excluded category is "not a hospital."

each of these three service categories, MC both significantly increases the number of services offered by FPs and decreases the number of services offered by publics.

MC does not appear to have a significant effect on NFP service offerings, with the exception of services within the medical testing group. 
Table 3: Effects of Managed Care on Service Categories-By Ownership*

\begin{tabular}{|c|c|c|c|c|c|c|}
\hline \multirow[b]{2}{*}{ Service Category } & \multicolumn{2}{|c|}{ For-Profit, $N=2,913$} & \multicolumn{2}{|c|}{$\begin{array}{c}\text { Not-for-Profit, } \\
N=6,447\end{array}$} & \multicolumn{2}{|c|}{ Public, $N=1,153$} \\
\hline & Coefficient & $P$-Value & Coefficient & P-Value & Coefficient & $P$-Value \\
\hline Assessment (2) & 0.119 & .036 & 0.104 & .235 & 0.046 & .133 \\
\hline Therapy/counseling (6) & 1.444 & $<.001$ & 0.066 & .540 & -1.225 & $<.001$ \\
\hline Medical testing $(6)$ & 0.895 & $<.001$ & -1.108 & .001 & -1.209 & .051 \\
\hline Transitional (5) & 1.132 & .001 & -0.197 & .290 & -0.773 & .063 \\
\hline Other ancillary (7) & -0.173 & .934 & -0.479 & .321 & -0.966 & .025 \\
\hline
\end{tabular}

*Boldface entries are statistically significant $(p$-value $<.100)$.

That is, MC significantly decreases the number of medical testing services offered by NFPs.

In addition, it appears that $\mathrm{MC}$ has a slightly positive impact on assessment services across all three ownership types (i.e., all three coefficients are positive and one of them is significant) and a slightly negative impact on other ancillary services across all three ownership types (i.e., all three coefficients are negative and one of them is significant).

\section{DISCUSSION}

One explanation for the differential impact of MC across facility ownership types is that $\mathrm{MC}$ results in standardization across facilities of different profit status. That is, in the absence of MC, we observe that FPs offer the narrowest range of services, publics the widest, and NFPs fall in the middle. Managed care could be a standardizing force making the service offerings more similar across ownership types. Thus, FPs add services while publics reduce them.

There are other possible explanations as well. For example, it may be that public and private SAT facilities have contracts with different types of MC organizations, which in turn may have different goals. For example, MC associated with state funding (e.g., block grants) may want to reduce the range of services offered in order to treat as many people as possible with limited funds. In contrast, private health insurance may have quality of care as a more important goal, and may therefore require additional types of treatment to increase effectiveness and offset other medical expenses.

The move from inpatient to outpatient settings associated with MC may also differentially impact facilities. If, for example, FPs treat more clients who, 
in the absence of MC, would be in inpatient care, then their client base would need a broader range of services in the presence of MC. Note that FPs may be more likely to treat those who otherwise would have been in inpatient care because their client base tends to have more generous coverage (which, in turn, may be more likely to cover inpatient care but for MC controls).

Empirically identifying which of the above reasons best explains the observed differential impacts, however, is beyond the capability of our data and is also beyond the scope of our paper.

The finding that MC significantly decreases wraparound service offerings (i.e., transitional services and other ancillary services) in public SAT facilities is consistent with Kapur and Weisbrod (2000) and Hodgkin et al. (2004), both of which found that public health care organizations respond to funding cuts by reducing quality of care, as opposed to turning away clients (i.e., publics view themselves as the "supplier of last resort"). ${ }^{6}$ It also supports Alexander, Lemak, and Campbell's (2003) speculation that as MC expands into the public SAT sector, cost containment may reduce the range and type of services available to vulnerable populations. The finding that MC appears to increase assessment services across all ownership types is consistent with the view that $\mathrm{MC}$ relies heavily on administrative controls such as utilization review.

This study is subject to a number of limitations. First, NSSATS records $\mathrm{MC}$ and specific service offerings as binary variables. Thus, we do not know the intensity, strength, or types of MC mechanisms at each facility; nor do we know whether a specific service has been received, who receives it, nor the intensity nor quality of the service. It is important to recognize, however, that using a binary indicator of MC and counts of binary indicators of specific services is a conservative approach. That is, the relatively blunt nature of binary variables could bias against finding significant results. Second, NSSATS does not collect data on client characteristics, so we cannot control directly for client mix. However, we mitigate potential omitted variable bias by using several proxies for client mix, including types of payment accepted and whether payment assistance is offered. Third, there may be some bias in the results for publics due to weak instruments. However, we expect this bias to be small given that the corresponding $F$-statistic (in Table 2) is both significant and much larger than 1.0 (Bound, Jaeger, and Baker 1995). Fourth, a general limitation of the IV approach is that it is not possible to prove the validity of the instruments used. While our instruments pass the overidentification test, it is still necessary to assume the validity of one of them to confirm the validity of the other. Although we believe that both instruments are in- 
tuitively plausible (as discussed in detail in "Methods"), others may disagree. Finally, approximately 20 percent of the facilities in NSSATS are missing one or more covariates used in the study and are therefore excluded from our final study sample. Although we have no reason to believe that data are missing in such a way as to bias the results (and we control for many important covariates including setting, modality, focus, and size), we cannot rule out this possibility.

We recognize that the aforementioned NSSATS data limitations constrain our analyses. Offsetting these limitations, however, is the fact that we have a large dataset that comprises a majority of SAT facilities in the U.S. and that contains data on a wide range of specific service offerings. Thus, our statistical power is high and our results are likely to be widely generalizable. Further, although we have only a crude measure of MC, we are able to move the literature forward by discovering interesting differential impacts of MC by provider profit status, thereby adding to both the SAT and ownership type literatures.

\section{CONCLUSIONS}

This study adds to the existing SAT literature by demonstrating that the impact of MC on SAT service offerings differs in magnitude and direction by facility ownership, and by quantifying these differential impacts. Specifically, MC significantly increases the number of services offered at private FPs, has no significant effect on the number of services offered at private NFPs, and significantly decreases the number of services offered at public SAT facilities. It appears that the differential impact of MC across ownership types is concentrated primarily in the therapy/counseling, medical testing, and transitional service categories. One possible explanation is that $\mathrm{MC}$ results in standardization of service offerings across facilities of different profit status. Our findings can be interpreted as causal, subject to the above limitations, because they are derived from IV models that not only control for relevant covariates but also adjust for potential endogeneity between $\mathrm{MC}$ and service offerings. ${ }^{7}$

Our findings raise policy concerns because a reduced range of service offerings in public facilities could result in unmet needs for SAT clients in these facilities. This, in turn, could lead to worse treatment outcomes for those in SAT as well as an increase in the negative externalities associated with drug abuse (e.g., unemployment, crime, spread of infectious diseases). On the other hand, FPs are found to increase their range of service offerings in response to 
MC. Further research is needed to better understand both the specific mechanisms of MC on SAT and the net impact on society.

\section{ACKNOWLEDGMENTS}

We would like to acknowledge financial support from the National Institute on Drug Abuse (NIDA R01-DA14471). We thank Mark Schlesinger, William White, and Mario Garcia for their valuable insights. We also thank Cathie Alderks of SAMHSA's Office of Applied Studies for data and helpful advice.

\section{NOTES}

1. Facilities were deemed ineligible for the survey if they were not providing substance abuse treatment as of October 1, 2002 or treated incarcerated clients only.

2. Other U.S. jurisdictions include the territories of American Samoa and Guam, the Federated States of Micronesia, the Republic of Palau, the Commonwealth of Puerto Rico, and the Virgin Islands.

3. The 2002 Area Resource File uses the InterStudy County Surveyor Database for the number of HMO enrollees in each county.

4. For information on bias due to weak instruments, see Bound, Jaeger, and Baker (1995) and Staiger and Stock (1997).

5. In practice, the test statistic is calculated as $N$ times the uncentered $R^{2}$ from regressing the IV residuals on all the instruments, and is distributed as a $\chi^{2}$ with degrees of freedom equal to the number of instruments in excess of the number of explanatory variables. For details on the overidentification test, see Davidson and Mackinnon (2004, p. 336-8; 1993, p. 232-7).

6. We consider the range of service offerings to be one component in the quality of care. Research shows that a greater range of services increases the effectiveness of care (McLellan et al. 1998, 1999; NIDA 1999). Payment to a SAT facility is not, however, typically explicitly determined by the number or range of services offered, but rather payment is made on a per diem or weekly basis. Thus, the range of services may be more akin to higher amenities or quality of care that are not paid for directly.

7. See Davidson and MacKinnon (1993, p. 209-42) or Greene (2003, p. 74-86) for a technical discussion of the properties of IV estimators. See McClellan and Newhouse (2000) or Dowd and Town (2002) for a nontechnical introduction to the IV approach with applications to health care.

\section{REFERENCES}

Alexander, J., C. Lemak, and C. Campbell. 2003. "Changes in Managed Care Activity in Outpatient Substance Abuse Treatment Organizations." Journal of Behavioral Health Sciences and Research 30 (4): 369-81. 
Bound, J., D. Jaeger, and R. Baker. 1995. "Problems with Instrumental Variables Estimation When the Correlation between the Instruments and the Endogenous Explanatory Variable Is Weak." Journal of the American Medical Association 90 (430): 443-50.

Davidson, R., and J. MacKinnon. 1993. Estimation and Inference in Econometrics. New York: Oxford University Press.

2004. Econometric Theory and Methods. New York: Oxford University Press.

Dowd, B., and R. Town. 2002. "Does X Really Cause Y?" AcademyHealth (National Program Office for Changes in Health Care Financing and Organization, an Initiative of The Robert Wood Johnson Foundation). Available at http:// www.hcfo.net/pdf/xy.pdf

Durkin, E. 2002. "An Organizational Analysis of Psychosocial and Medical Services in Outpatient Drug Abuse Treatment Programs.” Social Service Review 76 (3): 40629.

Ettner, S., M. Argeriou, D. McCarty, J. Dilonardo, and H. Liu. 2003. "How Did the Introduction of Managed Care for the Uninsured in Iowa Affect the Use of Substance Abuse Services?" Journal of Behavioral Health Services and Research 30 (1): $26-40$.

French, M. T., H.J. Salome, A. Krupski, J. R. McKay, D. M. Donovan, A. T. McLellan, and J. Durell. 2000. "Benefit-Cost Analysis of Residential and Outpatient Addiction Treatment in the State of Washington." Evaluation Review 24 (6): 609-34.

Friedmann, P., J. Alexander, and T. D’Aunno. 1999. “Organizational Correlates of Access to Primary Care and Mental Health Services in Drug Abuse Treatment Units." Journal of Substance Abuse Treatment 16 (1): 71-80.

Friedmann, P., S. Lemon, E. Durkin, and T. D'Aunno. 2003. "Trends in Comprehensive Service Availability in Outpatient Drug Abuse Treatment." Journal of Substance Abuse Treatment 24 (1): 81-8.

Friedmann, P., S. Lemon, M. Stein, and T. D’Aunno. 2003. “Accessibility of Addiction Treatment: Results from a National Survey of Outpatient Substance Abuse Treatment Organizations." Health Services Research 38 (3): 887-903.

Gould, F., M. Levine, and A. T. McLellan. 2000. "Treating the Substance-Abusing Patient in the Public Sector: 'Medical Necessity' versus 'Social Necessity and Social Responsibility' in the Philadelphia Target Cities Demonstration Project." Journal of Substance Abuse Treatment 18 (1): 75-7.

Greene, W. 2003. Econometric Analysis. 5th Edition. Upper Saddle River, NJ: Prentice Hall.

Harwood, H., D. Fountain, and G. Livermore. 1998. The Economic Costs of Alcohol and Drug Abuse in the United States, 1992. NIH Publication No. 98-4327. Rockville, MD: National Institute on Drug Abuse.

Hodgkin, D., D. Shepard, Y. Anthony, and G. Strickler. 2004. “A Publicly Managed Medicaid Substance Abuse Carve-Out: Effects on Spending and Utilization." Administration and Policy in Mental Health 31 (3): 197-17.

Institute of Medicine 1990. Treating Drug Problems-Volume 1: A Study of the Evolution, Effectiveness, and Financing of Public and Private Drug Treatment Systems. Washington, DC: National Academy Press. 
Jofre-Bonet, M., and J. L. Sindelar. 2001. "Drug Treatment as a Crime Fighting Tool." The Journal of Mental Health Policy and Economics 4 (4): 175-8.

Kapur, K., and B. Weisbrod. 2000. "The Roles of Government and Nonprofit Suppliers in Mixed Industries." Public Finance Review 28 (4): 275-308.

Maddala, G. 1983. Limited-Dependent and Qualitative Variables in Econometrics. New York: Cambridge University Press.

Marsh, J., T. D'Aunno, and B. Smith. 2000. "Increasing Access and Providing Social Services to Improve Drug Abuse Treatment for Women with Children." Addiction 95 (8): 1237-47.

McClellan, M., and J. Newhouse. 2000. "Introduction: Overview of the Special Supplement Issue-Instrumental Variables Analysis: Applications in Health Services Research." Health Services Research, 35 (5, Part II).

McLellan, A. T., I. Arndt, D. Metzger, G. Woody, and C. O'Brien. 1993. "The Effects of Psychosocial Services in Substance-Abuse Treatment." Journal of the American Medical Association 269 (15): 1953-9.

McLellan, A. T., T. Hagan, K. Meyers, M. Levine, F. Gould, M. Bencivengo, J. Durell, and J. Jaffe. 1998. "Supplemental Social Services Improve Outcomes in Public Addiction Treatment." Addiction 93 (10): 1489-99.

McLellan, A. T., M. Levine, T. Hagan, K. Meyers, M. Randall, F. Gould, M. Bencivengo, and J. Durell. 1999. "Does Clinical Case Management Improve Outpatient Addiction Treatment?" Drug and Alcohol Dependence 55 (1-2): 91-103.

Milby, J., J. Schumacher, J. Raczynski, E. Caldwell, M. Engle, M. Michael, and J. Carr. 1996. "Sufficient Conditions for Effective Treatment of Substance Abusing Homeless Persons." Drug and Alcohol Dependence 43 (1-2): 39-47.

National Consensus Development Panel on Effective Medical Treatment of Opiate Addiction. 1998. "Effective Medical Treatment of Opiate Addiction." Journal of the American Medical Association 280 (22): 1936-43.

National Institute on Drug Abuse (NIDA), National Institutes of Health, U.S. Department of Health and Human Services. 1999. Principles of Drug Addition Treatment: A Research Based Guide. NIH Publication No. 99-4180. Washington, DC: National Institutes of Health.

Office of National Drug Control Policy. 1996. "Treatment Protocol Effectiveness Study: A White Paper of the Office of National Drug Control Policy.” Journal of Substance Abuse Treatment 13 (4): 295-320.

- 2001. The Economic Costs of Drug Abuse in the US, 1992-1998. Publication No. NCJ190636. Washington, DC: Executive Office of the President.

Olmstead, T., and J. Sindelar. 2004. "To What Extent Are Key Services Offered in Treatment Programs for Special Populations?” Journal of Substance Abuse Treatment 27 (1): 9-15.

Olmstead, T., W. White, and J. Sindelar. 2004. "The Impact of Managed Care on Substance Abuse Treatment Services." Health Services Research 39 (2): 319-45.

Rodgers, J., and P. Barnett. 2000. "Two Separate Tracks? A National Multivariate Analysis of Differences between Public and Private Substance Abuse Treatment Programs." American Journal of Drug and Alcohol Abuse 26 (3): 429-42. 
Smith, B., and J. Marsh. 2002. "Client-Service Matching in Substance Abuse Treatment for Women with Children." Journal of Substance Abuse Treatment 22 (3): 161-8.

Staiger, D., and J. Stock. 1997. "Instrumental Variables Regression with Weak Instruments." Econometrica 65 (3): 557-86.

U.S. Department of Health and Human Services, Health Resources and Services Administration, Bureau of Health Professions, National Center for Health Workforce Analysis. 2002a. Area Resource File. Washington, DC: U.S. Department of Health and Human Services.

U.S. Department of Health and Human Services, Substance Abuse and Mental Health Services Administration, Office of Applied Studies. 2002b. National Survey of Substance Abuse Treatment Services (N-SSATS), 2000 [United States] [Computer file]. ICPSR Version. Arlington, VA: Synectics for Management Decisions, Inc. [producer]; Ann Arbor, MI: Inter-University Consortium for Political and Social Research [distributor].

Wheeler, J., and T. Nahra. 2000. "Private and Public Ownership in Outpatient Substance Abuse Treatment: Do We Have a Two-Tiered System?" Administration and Policy in Mental Health 27 (4): 197-209.

Wooldridge, J. 2002. Econometric Analysis of Cross Section and Panel Data. Cambridge, MA: The MIT Press. 